\title{
LAS INCONSISTENCIAS DIALÓGICAS EN EL DEBATE PÚBLICO EN MATERIA DE GÉNERO*
}

\section{The dialogical inconsistences of public debate on gender related issues}

Camila Herrera Pardo**

Recepción: 27/11/2019. Aceptación: 29/12/2019

DOI: http://dx.doi.org/10.21017/Rev.Repub.2020.v28.a80

\section{RESUMEN}

En el presente artículo se examinan las razones que hacen especialmente difícil y tortuoso el debate público en materia de género. Sin pretensiones de exclusividad o exhaustividad, se sostiene que en este ámbito temático usualmente se presentan varias disfuncionalidades de orden lógico y argumentativo que terminan haciendo imposible un diálogo genuino y hacen que la discusión degenere en intercambio de eslóganes entre partes que no se oyen.

Palabras clave: Diálogo, argumentación, género, feminismo.

\begin{abstract}
This article explores the reason that explain the particular difficulties of the public debate about gender issues. Without pretensions of exclusivity or exhaustivity, the paper claims that the public discourse on this topic is marked by several logical and argumentative dysfunctionalities that at the end, make genuine dialogue impossible and instead lead to a exchange of slogans among deaf parties.
\end{abstract}

Key words: Dialogue, Argumentation, gender, feminism.

* Artículo producto de investigación que desarrollo la autora sobre el tema.

** Profesora de la Facultad de Derecho y Ciencias Políticas de la Universidad de La Sabana, Campus Universitario del Puente del Común, $\mathrm{Km}$ 7, Autopista del Norte de Bogotá, Chía, Cundinamarca, Colombia. Orcid. No. 0000-0001-6018-6167. E-mail: camila. herrera@gmail.com 


\section{PUNTO DE PARTIDA: OBSERVACIONES Y PLANTEAMIENTO DEL PROBLEMA}

El tema de género no parece ser, en ninguna parte, un asunto pacífico. Eventos ocurridos en campus universitarios de varias latitudes, pero especialmente del mundo anglosajón, evidencian la peculiar dificultad de mantener los diálogos académicos sobre género en el nivel de la civilidad y preservar el rigor científico en la discusión. Los casos son varios. Conferencias truncadas por voces de protesta, académicos vetados, eventos en los que un expositor, a gritos y con improperios, intenta responder a las rechiflas de un público francamente hostil. Gritos, lágrimas e incluso heridos. ${ }^{1}$ Fuera del ámbito académico la situación es francamente peor. Mediática y políticamente, los debates -si es que así se pueden llamar- sobre género abundan en argumentos falaces, y con aún mayor frecuencia degeneran en violentas diatribas, o actos de vandalismo. Dada la dificultad de un diálogo genuino en estas condiciones no sorprende que lo que ocurra en la realidad es que se creen comunidades intelectuales o políticas totalmente cerradas en sí mismas, en las que ciertos temas y posturas son anatematizados, y los mismos discursos se repiten una y otra vez, sin ser cuestionados.

Siendo esta la situación parece importante preguntarse, ¿Qué es lo que impide hablar razonablemente de temas relacionados con géneró ¿por qué estas peculiaridades del debate sobre este temá $Y$, ¿qué se puede hacer para subsanarlas?, Muchas de estas se han intentado explicar aludiendo a características generacionales o culturales.

1 Ejemplo paradigmático de esta situación pueden ser las polémicas conferencias de Milo Yiannopolous en diversos escenarios académicos de los Estados Unidos. Por una parte, el controvertido periodista, sube al escenario en actitud de franca provocación, y no en pocas ocasiones insulta a sus detractores afirmando, por ejemplo, que alguien es feminista porque es "horrible", o simplemente llamándola "golfa". Por otra parte, los opositores a Yiannopoulos (conformados en parte, aunque no exclusivamente, por agrupaciones feministas) organizan boycotts a sus charlas, llegando en ocasiones a la violencia física. Así, por ejemplo, una de sus presentaciones en la Universidad de Berkeley, California, concluyó con manifestaciones violentas, intervención policial y cuatro heridos. Iguales reacciones han tenido lugar con expositores de mayor peso académico, cuyo discurso no es deliberadamente provocador, como sí lo es el de Yiannopoulos. Por citar ejemplos, de académicos de otro perfil que han sido recibidos con protestas y trifulcas, recuerde el lector los incidentes de profesores como Jordan Peterson y Jannice Fiamingo en universidades canadienses o Christine Hoff Sommers en universidades norteamericanas. Igualmente, dicientes son los ataques mediáticos y por redes sociales al activista por los derechos homosexuales Peter Tatchell y la profesora Mary Beard, después de publicar un manifiesto en defensa de la libertad de expresión, considerado "transfóbico" y la reciente petición de excluir al profesor John Finnis de la Universidad de Oxford, por sus posiciones sobre el matrimonio y la homosexualidad. 
Sin embargo, un análisis más profundo de dinámicas del diálogo en esta materia revela la recurrencia de situaciones inconsistentes con los teóricos han identificado como reglas del diálogo racional, tema que será abordado en el presente estudio. Para efecto de este artículo se tomarán como referencia de racionalidad dialógica algunas de las reglas expresadas por Robert Alexy. No se hará una confrontación entre lo que se acercaría a una situación ideal del habla o un diálogo plenamente racional mediante la revisión exhaustiva de cada una de las reglas, sino que simplemente se ofrecerán pinceladas sobre las irregularidades argumentativas más prominentes.

\section{IRREGULARIDADES Y DIFICULTADES RELATIVAS A LAS REGLAS FUNDAMENTALES DE LA ARGUMENTACIÓN Y EL DIÁLOGO.}

Tal vez lo que más llama la atención al examinar las dinámicas de los debates en materia de género sea la frecuencia y la intensidad con que se incumplen lo que Alexy llama las reglas fundamentales de la argumentación. Como bien lo señala el profesor alemán, se trata de reglas cuyo cumplimiento es "condición de posibilidad de cualquier comunicación lingúística en que se trate de la verdad o corrección" (Alexy, 2017, p. 266). En este sentido, se puede decir que se trata de reglas tan básicas que su incumplimiento no hace inválido o defectuoso el diálogo racional sino que pura y simplemente lo imposibilita.

Dentro del catálogo de reglas fundamentales de la argumentación, Alexy señala estos cuatro requisitos:

“ (I)Ningún hablante puede contradecirse; (II). Todo hablante sólo puede afirmar aquello que él mismo cree; (III) Todo hablante que aplique un predicado F a un objeto a debe estar dispuesto a a aplicar $\mathrm{F}$ también a cualquier otro objeto igual a a en todos los aspectos relevantes y (V) Distintos hablantes no pueden usar la misma expresión con distintos significados"(Alexy, 2017, p. 266).

La observación atenta del panorama del diálogo académico y político en materia de género revela que, sorprendentemente, muchas de estas condiciones no solo no están presentes sino que son abiertamente impugnadas.

\subsection{El cuestionamiento de la lógica}

La primera de las reglas fundamentales, que Alexy enuncia en términos de no contradicción, expresa una remisión a las reglas lógicas (2017, p. 266). El diálogo racional exige, como presupuesto, la aceptación de estas reglas. 
Lo anterior resulta problemático dado que, justamente, la crítica dirigida por ciertos sectores de la teoría de género, cuestiona el papel de la lógica. Y es que, a pesar de su aparente neutralidad, la lógica misma ha sido y asociada a modelos de pensamiento "patriarcal". Por citar un caso conocido, en un famoso escrito, Andrea Nye (1990), dirige a toda la lógica occidental, empezando por la griega y terminando en los autores del siglo XX, una deletérea crítica. Así, a partir de la defensa del matricida Orestes ante las furias, construida sobre la base de razonamientos silogísticos, sostiene que la forma del silogismo y de la lógica formal, en general, dotan a las ideas sexistas de la apariencia de verdades necesarias e incuestionables (Nye, 1990, p. 59). Y va más allá para sostener que la lógica "emerge únicamente en el contexto de la opresión y la dominación y eleva los elementos formales del lenguaje, suprimiendo o borrando los contextos de los que las expresiones derivan su significado" (Hass, 1998, p. 25). En el mismo sentido, la autora llega a vincular la lógica fregeana, con la legitimación de la violencia contra la mujer, el ascenso del nacional-socialis$\mathrm{mo}^{2}$, o a afirmar que las matemáticas, la física o la computación son cotos patriarcales a los que no llega la necesaria apertura al feminismo debido a la "la insistencia en reglas lógicas [gramáticas, semánticas y de uso de las palabras] que llevan implicación sexistas" (Nye, 1998, p. 153). ${ }^{3}$

Otras autoras como Luce Irigaray cuestionan la lógica tradicional. Sus afirmaciones son contundentes. La lógica occidental, y en especial, el modo de entender el principio de no contradicción llevan en sí el germen de categorizaciones binarias vinculadas a modelos patriarcales. En concreto, la estructura lógica occidental, con un alto grado de parcialización, tiende a reducir la diferencia a negación, y, por lo tanto, a la minusvalorización de lo diverso. Que la mujer sea "diferente al hombre", en lógica tradicional, tanto aristotélica, como moderna, sostiene Irigaray, equivale a concebirla como "no hombre" y por lo tanto a no percibir la riqueza de su modo específico de ser (Hass, 1998, p. 25).

Por otra parte, la misma Irigaray, cuestiona las estructuras de la ciencia occidental, cuya neutralidad estima aparente y encubridora del un isomorfismo patriarcal. En concreto, su exigencia de expresar los descubrimientos científicos en el lenguaje de la lógica formal que desconoce la diferencia no cuantitativa, o el movimiento o la fluidez (Irigaray, 2008, pp. 283-292).

Ahora bien, la enunciación sumaria, por exigencias metodológicas, y meramente ilustrativa de la lógica, clásica y moderna por parte de ciertas teóricas

2 Precisamente estos aspectos son resaltados en la resena de Joan Weiner sobre la

3 La cita es tomada de la traducción de Barceló Aspeitia (2004). 
feministas, puede llevar a la aceptación de estereotipos simplistas del tipo "feministas contra la lógica" (Barceló Aspeitia, 2004). Dicho estereotipo supone dos problemas. El primero, el de la generalización. En efecto, resulta simplemente incorrecto sostener que todos los autores feministas impugnan el papel y la función de la lógica. De hecho, como bien lo ha señalado Barceló, algunos párrafos de reputadas autoras feministas, demuestran contundentemente la falsedad del estereotipo de una "guerra contra la lógica" por parte de "el" feminismo. Así, por ejemplo, el siguiente párrafo de Susan Sherwin (citado por Barceló, para ilustrar su punto), es sencillamente incompatible con la idea de minusvaloración de la lógica:

The logic of the argument is the most important feature of a philosophical position, far more important than the plausibility of the claims or the usefulness of the insight to other questions... In feminist scholarship, logic is also important - as Richards et al. take delight in pointing out - and theories that are logically flawed, or clearly false, or lacking in explanatory power are subject to criticism among feminists as well. But feminists have political as well as intellectual aims, which they are quite willing to admit to ([other] philosophers have political agendas as well ..., but ... few ... will admit to ...) ... The effect, as well as the logic, of a theory is significant. A theory that did not contribute to political change is of only limited interest. In other words, feminist view political effects as one measure of acceptability, though certainly not the only measure (Barceló Aspeitia, 2004, pp.36-37).

Así, pues, la crítica feminista "a la lógica" debe entender circunscrita a ciertas corrientes $\mathrm{y}$, muchas veces, vinculada más al posestructuralismo que inspira esas corrientes en particular, que a su postura concreta sobre el género (Barceló Aspeitia, 2004, p. 4).

En segundo lugar, se ha de tener especial cuidado en distinguir qué es específicamente lo cuestionado por estas teorías. En efecto, una negación pura y simple de la lógica y, en concreto, de sus principios medulares y evidentes (en concreto del principio de no contradicción) excluye por completo la posibilidad de un intercambio científico y un debate racional. Todo el edificio científico y toda conversación razonable se estructuran sobre la aceptación de que una afirmación y su negación no pueden ser ciertas, al mismo tiempo y en el mismo sentido; o si se quiere, de que no se puede ser y no ser al mismo tiempo y bajo el mismo aspecto.

Sin embargo, una lectura atenta de alguna de estas impugnaciones revela que la cuestión es mucho más sutil y que algunas invitan a re-planteamienos bastante interesantes. Así, por ejemplo, si bien las impugaciones de Nye contra la lógica parecen exageradas, sí parece razonable cuestionar el modo, tam- 
bién denunciado por esta autora, de reducción del razonamiento práctico a estructuras formales, privadas de atención al contexto, el sentido o la finalidad. Que este tipo de reduccionismo no sea consecuencia de "la lógica" o de "toda lógica", es algo que se hace patente al considerar que, en el corazón de los escritos de Aristóteles -aquel a quienes una gran parte de la crítica feminista considera como padre de la lógica binaria reduccionista- hay una clarísima admonición sobre los peligros de razonar en asuntos prácticos esperando la misma precisión que en las matemáticas (Ética a Nicómaco, 1094b-27; 1098a 27-29). ${ }^{4}$

Por otra parte, aunque, en opinión de quien escribe, la equiparación de la aceptación del principio de no contradicción, no conduce, en Aristóteles, a la necesaria aceptación de modelos binarios de pensamiento, como sostiene Irigaray, ${ }^{5}$ no se puede negar que, a partir de la modernidad, existe una marcadísima tendencia a la aceptación de una conceptualización binaria, con una lógica típicamente disyuntiva, a la minimización de la polivalencia y la ambivalencia, y a concebir la identidad en términos meramente cuantitativos (Irigaray, 2008, pp. 283-292). Esta tendencia a la minimización y a la esquematización, prioritariamente cuantitativa, no es producto, necesariamente, de la aceptación de un modelo lógico basado en la identidad, la no contradicción y del tercero excluido, sino, más bien, en un modo de conceptualización basado en una ontología univocista, que negando la analogía, obliga a la disyuntiva entre ser idénticamente o no ser.

En todo caso, lo que parece indiscutible es que, si la mayor parte de la ciencia occidental -incluidas las ciencias sociales- se estructura sobre una manera de concebir la lógica, el reclamo, por parte de un sector de la teoría de género, de que ese modo de pensar está esencial o accidentalmente viciado y parcializado, obliga a detener momentáneamente el diálogo científico en materias como la identidad de sexo y de género, para llevar el diálogo y la reflexión al campo epistemológico. No se trata de "negociar" o "consensuar" las reglas de la lógica, sino de repensar, en qué consisten estas, hasta dónde es necesaria y suficiente la formalización en materias prácticas, qué quiere decir exactamente el principio de contradicción, a qué formas de relación conceptual u oposición aplica, cuál es el papel de los elementos cualitativos, etc.

4 La traducción que se utiliza en este escrito es la de Julio Pallí Bonet, ver Aristóteles (1985).

5 Ello porque en la lógica aristotélica, aparte de la oposición contradictoria propiamente dicha, se cuentan otras formas de oposición como la privación, la correlación y la contrariedad, en las cuales no opera la exclusión total que se da en la contradicción pura y simple y entre las cuales se contemplan múltiples maneras de ser distinto (cfr. Hass (1998, p. 35)). 
Así un movimiento en esta dirección entorpezca y retarde la discusión académica, en tanto que un sector mayoritario o no de los intervinientes en el debate de género impugne la estructura argumentativa, las posibilidades de formular argumentos de validez universal en el contexto del diálogo contemporáneo se disminuirá significativamente. En un contexto como este, la imposibilidad de diálogo se acabará resolviendo, necesariamente, por la exclusión de hablantes y, por consiguiente, por la imposición.

Queda, por otra parte, abierta la cuestión de las consecuencias de estas impugaciones de algunas de los principios fundantes de la lógica occidental por fuera del contexto científico. Mientras que en un escenario académico es perfectamente posible y necesario suspender la discusión y llevarla al plano lógico y epistemológico, tratándose de escenarios en los que urge la premura para la decisión (v.gr. juicios de tutela/amparo, discusiones sobre proyectos de ley), tal remisión no solo es inconveniente sino que resulta imposible. Notablemente, son escasísimos los casos en los que las cuestiones lógicas y epistemológicas salen a relucir en estos contextos. Sin embargo, para efectos prácticos se habrá de aceptar que dichas discusiones se suelen dar dentro del marco de un sistema instituido y formalizado, que incorpora dentro de sus principios estructurales, ciertas maneras de conceptualizar y razonar, cimentados, justamente, sobre la no contradicción. Las decisiones judiciales y políticas occidentales se entienden ordinariamente como resultados de un proceso, que es, entre otra cosas, concatenación lógica de acciones y argumentos. En este sentido, para argumentar dentro de este sistema, es preciso, acatar sus principios lógicos estructurantes.

\subsection{La disolución de la confianza y la regla de sinceridad}

Quienes han teorizado sobre la acción comunicativa coinciden en un punto fundamental: el presupuesto de todo diálogo es la sinceridad. Todo hablante se compromete a expresar lo que realmente piensa y puede esperar, por otra parte, que su interlocutor manifieste, efectivamente, su pensamiento e intenciones. En otras palabras, se presupone la buena fe de los hablantes, excluyéndose, por lo tanto, el uso engañoso del lenguaje o una actitud dolosa encaminada a inducir al error.

Esta regla, hay que entender, implica, por una parte, el compromiso de uso ético del lenguaje, pero también, y en igual medida, la existencia de una cierta confianza respecto del otro. De hecho, en cierto modo, la regla de sinceridad, entendida como exigencia de buena fe, tiene sentido prioritariamente en la medida en que protege el bien humano de la confianza. Dejando de lado el campo de la negociación, una discusión racional se hace prácticamente imposible, si se da por supuesto, que aquello que manifiesta el interlocutor es una 
fachada engañosa. En estos casos, cada hablante termina respondiendo, no a lo que efectivamente ha dicho su contraparte, sino de lo que presume unilateralmente que esconde el discurso manifiesto.

Lo anterior tiene relevancia toda vez que en el debate sobre género es recurrente la atribución de intereses y prejuicios subrepticios en el discurso del interlocutor, e incluso, una intención de enmascarar bajo una argumentación aparentemente neutra o científica, proyectos de aniquilación, odio o aversión, o la intención de subversión total de las estructuras más básicas de la sociedad. A ello contribuye, por lo menos hasta cierto punto, la filiación marxista y posmoderna un sector del feminismo y de las teorías queer.

Por una parte, el hecho de que buena cantidad de las teorías de género beban del marxismo y de las filosofías posmodernas, las hace herederas de una hermenéutica de la sospecha (Ricoeur, 1999, p. 33 y ss.), es decir, de una comprensión del discurso como vehículo de estructuras de poder e intereses hegemónicos, o pulsiones primarias. Es de notar que, como bien recuerda Paul Ricoeur, filósofos como Marx, Nietzsche y Freud, a quienes, como es sabido, atribuye el título de "maestros de la sospecha", no solo consideran que el discurso esconde estructuras y motores distintos a los que se presentan expresamente, sino que disuelven al sujeto y a la conciencia, a fachadas, expresiones de las fuerzas reales. En este sentido, la consecuencia obvia de este tipo de hermenéutica es un cierto oscurecimiento de confianza en el diálogo, incluso si se aceptara la "buena fe" consciente del interlocutor. Y es que si el "yo" es una ilusión, si la autocomprensión es represión, o resultado de fuerzas materiales inconscientes, el hecho de que el interlocutor no tenga consciencia de ocultar dolosamente sus verdaderas razones e intereses, no quiere decir que el discurso en sí mismo sea confiable, o realmente signifique lo que quien lo pronuncia "cree decir". En este sentido, la regla de sinceridad pasa a ser superflua y el efecto de producción de confianza, auténtico requisito del diálogo, se afecta.

Ello no quiere decir, necesariamente, que dadas las coordenadas teóricas de las filosofías de la sospecha resulte imposible entablar un diálogo real. De hecho, algunas de estas posturas -v.gr. la freudiana- abiertamente propugnan por métodos que permiten conocer y hacer explícitas las fuerzas que yacen debajo del yo, y que, por ende, condicionan en discurso "consciente" (Rivelis, 2009, p. 16). Razones metodológicas impiden ocuparse de la cuestión de la eficacia de estos métodos, fervorosamente impugnados y defendidos. Por otra parte, aún cuando estos paradigmas rechazan radicalmente el ego del cogito cartesiano, ello no se sigue necesariamente que desde estos paradigmas no quepa un cierto reconocimiento de un yo, en sentido débil. 
Empero, si la filosofía de la sospecha es interpretada "gnósticamente", entendiendo por ello, en términos de conocimiento de una verdad "inaccesible" a los legos, y reservada, en cambio, a unos cuantos "iluminados", el diálogo deviene auténticamente imposible. Así, por ejemplo, si uno de los interlocutores se presenta a sí mismo como libre de los condicionamientos que las estructuras de poder imponen a la conciencia, pero conocedor absoluto de la persistencia de esos condicionamientos inconscientes en el discurso de su interlocutor, el diálogo pierde todo sentido y posibilidad.

La filiación marxista de varias de las corrientes teóricas más representativas en materia de género tiene, a su vez, otra consecuencia significativa en lo que respecta a la confianza dentro del diálogo. Debido a una serie de generalizaciones que en este escrito deben considerarse inadecuadas, algunos parten del hecho histórico de que gobiernos y partidos comunistas hayan aceptado la mentira como estrategia política, para atribuir a todas las corrientes intelectuales directa o indirectamente asociadas al marxismo un uso estratégico de la mentira y a una actuación sistemática de mala fe. Este tipo de caracterizaciones tiene como única consecuencia posible la imposibilidad de diálogo, tal y como queda diáfanamente manifiesto en el siguiente pasaje de una de las más importantes críticas a las corrientes de género escritas en América Latina:

Si hay alguna herramienta utilizada por estos sectores a la hora de forjar el desconcierto y ganar terreno en esta batalla psico-política, es justamente la del lenguaje. Para tal fin, estos lobbystas no han escatimado en manosear el idioma y el sentido de las palabras, para luego acudir no sólo a su embestida propagandística sino también a la amable quimera del "diálogo" como herramienta de "persuasión civilizada": "No hay dicotomía entre diálogo y acción revolucionaria. No hay una etapa para el diálogo y otra para la revolución. Al contrario, el diálogo es la esencia misma de la acción revolucionaria" sostenía el agente marxista Paulo Freyre, pedagogo brasileño oriundo de Pernambuco (suerte de Antonio Gramsci tercermundista), quien tanto influyó con su famosa obra Pedagogía del oprimido publicada en 1968 (Márquez \& Laje, 2016).

Idénticas formas de satanización de un hablante pueden encontrarse en el otro extremo del espectro argumentativo. La identificación de las posturas críticas al aborto, el matrimonio homosexual, o de ciertas manifestaciones del discurso de género como formas de peligroso fanatismo religioso que odia a ciertos colectivos es omnipresente. Así, por ejemplo, P. Radosh, describe a los líderes de los movimientos pro-vida de los Estados unidos como hombres que por motivos religiosos están interesados en mantener la subordinación de la mujer y sostiene que, aunque estos usualmente apelen públicamente a argumentos basados en el respeto a la vida y a la condición humana del no nacido, lo cierto 
es que su motivación más fuerte se halla en su compromiso con la estructura patriarcal:

Leaders of these organizations are often men who believe deeply that family life requires a divinely ordained system of patriarchy. Women who support these organizations also believe that women are biblically required to serve men in marriage and that abortion not only interrupts a divinely ordained order, but also challenges the God-man-woman hierarchy.

Issues of power still dominate the abortion debate: only the domain of power has shifted. Those who advocate for abortion rights still maintain that the power to choose whether to parent should rest with women who must bear physical responsibility of reproduction. Those who advocate against abortion rights are not only those who want to control de procedure, but now also include those who want's to control women's lives and options. The $19^{\text {th }}$ and early $20^{\text {th }}$ century debates concerned who should provide services; the current debate focuses upon who should control women's lives. Those who advocate against abortion rights often believe on traditional restrictions on women's opportunities. To affirm abortion is, symbolically to affirm social, economic, political and reproductive choice, which is usually incompatible with the moral values and beliefs of those who oppose abortion rights. While moral issues related to life, conception and divine intervention in the initiation of life are the forefront of anti-abortion arguments, the moral issues in the second tier of the debate generally return to social, political and reproductive freedoms for women, which threaten traditional views. (Radosh, 2009, p. 31)

Dicho sea de paso que esta suerte de generalizaciones, del tipo, "porque $\mathrm{X}$ es comunista/provida/feminista/cristiano/activista Lgtbi/capitalista, etc, seguramente miente", no solamente destruye la confianza que presupone el diálogo sino que constituye, técnicamente hablando, una forma de razonamiento falaz. Más propiamente, en este esquema argumentativo cabe advertir las falacias ad hominem (tanto abusivo como circunstancial) y de accidente inverso.

En síntesis, en parte las dificultades que presenta el diálogo en materia de género derivan de la creciente disolución de la confianza, y por lo tanto, de la percepcion del interlocutor como "enemigo" y de su discurso como "fachada" o "trampa". Este ambiente argumentativo, no es exclusivo de los diálogos en materia de género, sino que, en gran parte, caracteriza a la discusión pública contemporánea. Sin embargo, las dificultades se acentúan en los temas de género, en parte, por el legado de algunas formas de hermenéutica de la sospecha, en parte, por las generalizaciones que existen sobre las tradiciones marxistas. Lo que interesa resaltar, sin embargo, es que mientras la discusión se perciba desde una óptica exclusivamente confrontativa, no habrá diálogo, 
puesto que, como se señaló ad supra, el diálogo y el debate, si bien enfrentan posturas, son en esencia una práctica colaborativa con un fin común (la verdad), es decir, cierta forma -analógica, si se quiere- de amistad.

\section{DIVERSIDAD DE SIGNIFICADOS E INEXISTENCIA DE UN LENGUAJE COMÚN}

Otra de las reglas fundamentales del diálogo, señaladas, ad supra es la del uso común del lenguaje (Alexy, 2017, pp. 269-270), condición que se rompe cuando, los hablantes emplean las mismas palabras bajo una significación diametralmente diferente. Se trata de supuestos en los que la homonimia, la ambigüedad, la vaguedad y la analogía de un término ocultan la existencia de discursos paralelos. Es decir, se habla de cosas distintas con las mismas palabras, en cierto caso, de modo insconsciente.

El diálogo sobre el género parece ser un caso paradigmático de escenario en el que la falta de un lenguaje común multiplica los desacuerdos. Es tanta la cantidad de estudios sobre género, tantos los matices que se han dado a conceptos como "género", "patriarcado" o"feminismo", que pretender unas significación monolítica de los mismos raya en la ingenuidad. Es de notar también la vaguedad y la ambigüedad de estos términos.

La pluralidad y diferencia de las maneras de entender el género ha sido puesta de relieve recientemente por las profesoras Ángela Aparisi, Blanca Castilla y Martha Miranda en su estudio sobre "Los discursos sobre el género", convenientemente en plural (Miralles, Castilla de Cortázar, \& Miranda Novoa, 2017, pp. 21109). Concretamente, las profesoras Aparisi, Castilla y Miranda han identificado cinco modelos radicalmente diferentes de entender las relaciones entre sexos y cuatro maneras de comprender la iguadad sexual y de género. Cada uno de estos paradigmas conceptualiza, valora y jerarquiza de modo sustancialmente diferente las nociones de género, sexo, masculinidad, feminidad, igualdad, opresión o patriarcado. Con excepción de lo que en su estudio se denomina modelo patriarcal, todos podrían reclamar para sí la calificación de feministas o de discursos contra la desigualdad.

Desde luego, existe un núcleo común y muy básico de significado en el que la mayoría de las formas de comprensión del género y la igualdad sexual pueden coincidir, y en los que existe un relativo consenso. Así, al menos en el ámbito occidental, no existe debate acerca de la conveniencia de la voz "discriminación" para referirse a políticas que, por ejemplo, limiten el acceso de la educación a los varones. Pero tal consenso parece disolverse cuando se va más allá de los casos más obvios. Concretamente, la misma noción de discriminación, 
utilizada como ejemplo, resultaría definida en términos casi contradictorios a la luz de modelos como el postfeminismo y el feminismo de la complementariedad, toda vez que, mientras que para uno la discriminación podría llegar cobijar cualquier forma de reconocimiento de diferencias naturales entre los sexos, el otro modelo entendería que, por el contrario, la falta de atención sobre las diferencias reales, que priva a cada sexo de su propia riqueza y sus propias aportaciones, también constituye una forma de discriminación, en tanto que, somete la diversidad humana a una lógica de uniformidad en la que subyace una cierta minusvaloración de lo peculiar de cada uno.

Ahora bien, si se examina el tratamiento de los temas relacionados con la sexualidad y el género en la actualidad pueden observarse clarísimamente los efectos de entender unívocamente expresiones cuyo significado varía notablemente según el marco de comprensión. El caso el plebiscito de paz en Colombia resulta especialmente útil para comprender las dificultades que se derivan de la polisemia de los términos. En efecto, en Colombia el significado de expresiones como perspectiva o enfoque de género, contenidos en el acuerdo de paz del gobierno colombiano con el grupo guerrillero Fuerzas Armadas Revolucionarias de Colombia (Farc), llegó a ser centro de la discusión política nacional. Este documento de 310 páginas, incluye dentro de sus principios de implementación el de igualdad y enfoque de género, definido, por el mismo documento, en estos términos:

Reconocimiento de las mujeres como ciudadanas autónomas, sujetos de derechos que, independientemente de su estado civil, relación familiar o comunitaria, tienen acceso en condiciones de igualdad con respecto a los hombres a la propiedad de la tierra y proyectos productivos, opciones de financiamiento, infraestructura, servicios técnicos y formación, entre otros; atendiendo las condiciones sociales e institucionales que han impedido a las mujeres acceder a activos productivos y bienes públicos y sociales. Este reconocimiento implica la adopción de medidas específicas en la planeación, ejecución y seguimiento a los planes y programas contemplados en este acuerdo para que se implementen teniendo en cuenta las necesidades específicas y condiciones diferenciales de las mujeres, de acuerdo con su ciclo vital, afectaciones y necesidades

Igualmente, en varias partes se menciona la necesidad de implementar algunas de las políticas públicas convenidas (v.gr. reparación integral, participación democrática, sustitución de cultivos ilícitos, etc), atendiendo al referido enfoque o a la perspectiva de género.

Como ya se mencionó, muy poco tiempo antes del plebiscito se desató en Colombia una fuerte polémica con ocasión de la circulación de unas cartillas de 
educación sexual con el sello del Ministerio de Educación, con un contenido muy afin al de los postfeminismos de género. Por otra parte, en uno de sus discursos, el jefe negociador del gobierno colombiano, Humberto de la Calle Lombana, al referirse al enfoque de género contenido en los acuerdos, citó a Simone de Beauvoir. Extractos de dicha conferencia se difundieron rápidamente. Los fragmentos más citados y reproducidos en medios de comunicación fueron:

En este punto conceptual, quiero hacer unas reflexiones que no comprometen a la Delegación. Son acercamientos de carácter personal.

En primer término, quiero retomar la gran diferencia entre el sexo y el género. Joan Scott citando a Fowler, dijo: "hablar de personas del género masculino o femenino, en el sentido del sexo masculino o femenino, es una expresión jocosa".

El sexo es una condición dada, mientras que el enfoque de género toca concepciones de carácter cultural que han generado estructuras de comportamiento social, que son históricas, en el sentido de que son productos sociales no deterministas. Son construcciones que abarcan patrones de comportamiento y de valoración asignados a cada género. Dijo Simone de Beauvoir: "no se nace mujer, se llega a serlo". Y hoy podríamos agregar también: "no se nace hombre, se llega a serlo". En cuanto a la población LGTBI se trata de asumir enfoques de orientación e identidad sexuales diversas (de la Calle Lombana, 2016a).

Dichas declaraciones, aunadas a la reciente publicación de las cartillas, dio lugar se desatara una oposición al acuerdo de paz, en razón de su postura sobre el género. Como se ha adelantado, este sector de la oposición interpretó las expresiones relativas al género y concretamente el término "enfoque de género" como prueba de el acuedo de paz estaba siendo empleado como una suerte de caballo de Troya para introducir veladamente una comprensión minoritaria de la sexualidad y el género, como ideología oficial y obligatoria.

Así por ejemplo, días antes del plebiscito, el exprocurador Alejandro Ordóñez manifestó:

Colombia marchó hace un mes cuando el gobierno nacional intentó imponer mediante una cartilla la ideología de género en las escuelas colombianas, quitándole, robándole la inocencia a nuestros hijos, a nuestros nietos y el derecho a los papás de escoger la educación de sus hijos. El presidente Santos esa misma noche lo negó. Dijo que nunca el gobierno, ni antes ni después, desarrollaría esa política. 
Ahora, en los acuerdos de la Habana, aparecen nuevamente y con infinita intensidad. Ya no será la ideología de género impuesta a nuestros hijos mediante una cartilla, sino que estará en la constitución. El gobierno y las FARC pretenden que la ideología de género quede como norma constitucional. Desde luego, no la llaman así. La llaman "el enfoque de género" (Ordóñez Maldonado, 2016)

Y más explícitamente, expresó lo siguiente en una emisora sobre el significado del término "enfoque de género"

Tiene dos sentidos. Un sentido, el de la no discriminación de la mujer. El del reconocimiento de los derechos de la mujer, el de promoción de los derechos de la mujer. De acuerdo, no hay ninguna observación. Pero hay otro sentido, que aparece con los contenidos que se le reconocen ideológicamente hoy a la noción "género". Como bien lo explicó Humberto de la Calle cuando firmó el acuerdo parcial sobre el enfoque de género, como bien lo planteó la hoy vicefiscal general de la nación, que fue otra de las personas que negoció ese acuerdo de paz, como bien lo refiere la comandante Sandino, representante de la Farc (sic), la noción género, la novedad de la noción género es precisamente que este no tiene relación con el sexo, que no se nace hombre ni se nace mujer sino que se hace. Eso implica toda una nueva antropología que va a impactar políticas públicas de familia, políticas públicas de salud, que implica un nuevo concepto de familia, de matrimonio, filiación, de adopción, una nueva noción de persona, de autonomía, de libertad (Sánchez Cristo, 2016).

Paralelamente, desde varios sectores del equipo negociador y del gobierno, se aclaraba que la expresión "enfoque de género" tenía, en el contexto del acuerdo un significado mucho más restrictivo. El mismo jefe negociador del gobierno, cuyas palabras sirvieron de base a muchas de las críticas, se opuso a la versión de sus críticos y expresó en una columna periodística:

De manera falsa se ha venido difundiendo la información de que el Acuerdo de La Habana contiene elementos de la llamada ideología de género. No es cierto. Se trata de una maniobra para atacar el Acuerdo como un todo. Lo que hicimos en La Habana fue adoptar un enfoque de género que tuviera en cuenta las diferencias en las consecuencias dañinas del conflicto, reconociendo que la mujer ha sufrido un impacto enorme, no solo como víctima directa de graves crímenes, la violencia sexual entre ellos, sino también en su condición de hija, madre, esposa y, en muchos casos, responsable solitaria de la preservación del hogar. Este punto de partida implica el compromiso de acentuar en la mujer el proceso de reparación, así como instaurar políticas y herramientas concretas que atenúen, y a la larga supriman, la discriminación ancestral que ha sufrido la mujer. 
Vamos al texto y dejemos la especulación. En la página 10 del Acuerdo se lee: "Igualdad y enfoque de género: reconocimiento de las mujeres como ciudadanas autónomas, sujetos de derecho que, independientemente de su estado civil, relación familiar o comunitaria, tienen acceso en condiciones de igualdad con respecto a los hombres a la propiedad de la tierra y proyectos productivos, opciones de financiamiento, infraestructura, servicios técnicos y formación, entre otros; atendiendo las condiciones sociales e institucionales que han impedido a las mujeres acceder a activos productivos y bienes públicos y sociales. Este reconocimiento implica la adopción de medidas... teniendo en cuenta las necesidades específicas y condiciones diferenciales de las mujeres, de acuerdo con su ciclo vital, afectaciones y necesidades".

Y dentro del amplio marco de la no discriminación, la mención de la comunidad LGBTI busca un compromiso dirigido a evitar el gueto cultural que han padecido, en menoscabo de derechos fundamentales a toda persona.

El Acuerdo no toca los temas del matrimonio, la familia, las parejas del mismo sexo ni nada de lo que uno pudiera imaginar como ingrediente de la llamada ideología de género. Entendemos y respetamos la sensibilidad de estas disyuntivas morales. El enfoque de género corresponde exactamente a los principios constitucionales vigentes. Su única ideología es la Constitución.

Para quienes se oponen al Acuerdo en este punto, hay dos caminos: o entienden que han sido informados de manera sesgada, o aceptan que su verdadero propósito es mantener a la mujer confinada a patrones discriminatorios y a la población LGBTI presa de la homofobia (de la Calle Lombana, 2016b)

Está fuera de las posibilidades y propósitos de este escrito entrar a determinar cuál es la "verdadera intepretación" de la polémica expresión, y mucho menos si alguna de las dos partes trató de inducir a los votantes al error alterando o escondiendo el significado de esta expresión. Lo que importa resaltar de momento es que, en el momento mismo de votar, gran parte de la población no tenía claridad sobre lo que significaban las disposiciones normativas sometidas a su consideración. De hecho, años después del referido plebiscito subsisten los desacuerdos sobre el verdadero alcance de la expresión.

Circunstancias como la polisignificación y la textura abierta de los términos empleados en los debates sobre género, hacen perfectamente posible que dos hablantes utilicen los mismos términos sin llegar a entenderse entre sí. Quien entienda la expresión "enfoque de género" en el sentido de tener en cuenta la afectación especial que el conflicto supuso para las mujeres y la población 
homosexual, probablemente verá como exageración o incluso paranoia las aseveraciones de cierto sector de la opinión sobre el modo en que dicha expresión introduciría cambios en la estructura de la familia o la educación de los hijos. Quienes enfocaron la expresión, leyéndola desde las coordenadas conceptuales de ciertos discursos sobre el género que, efectivamente abogan por cambios como la desvinculación del matrimonio de la heterosexualidad, seguramente no pudieron entender cómo muchos leían una consagración casi textual de las ideas del posfeminismo de género, sin detéctalo.

Así mismo, que dos personas hayan manifestado diversas posturas respecto del acuerdo y su inclusión del enfoque de género, no necesariamente debe interpretarse como prueba de que efectivamente están en desacuerdo en cuestiones como el papel del Estado en la educación sexual, el aborto o el matrimonio homosexual. Puede darse perfectamente el caso de que dos personas que opinan exactamente lo mismo sobre esta materia, tengan posturas diametralmente opuestas sobre textos como los citados del referendo, por la simplísima razón de que les atribuyen significados diametralmente diferentes.

Cabe resaltar, por lo demás, que supuestos de incomunicación como el citado anteriormente son mucho más frecuentes de lo que se cree. Así, por ejemplo, muchos desacuerdos sobre el valor y las aportaciones "del" feminismo, realmente derivan del hecho de que mientras algunos reservan el término para referirse a las posturas de las últimas "olas" de este movimiento, otros lo usan en un sentido más amplio para referirse a cualquier forma de reivindicación de la igualdad femenina y de oposición a las dinámicas y estructuras sociales de subordinación de la mujer.

Supuestos de incomunicación o de comunicación defectuosa como los antedichos pueden ser explicados, en parte, por la tendencia -heredada de la modernidad- a reducir la complejidad a una simplicidad monísitica. Sin embargo, no se puede desconocer que en parte los desacuerdos para entender el lenguaje de género, y por lo tanto, para minimizar la incidencia de la equivocidad y la ambigüedad en el diálogo sobre estos temas, obedecen a una característica epistemológica especialmente acentuada en la era presente. En efecto, así como ocurre con todas las relaciones y estructuras sociales (Bauman, 2004, pp. 7-20), el significado de términos como "familia", "género", o "paternidad", tiende a la licuefacción. Esto ya lo advertía en 1999 el sociólogo Ulrich Beck, en una entrevista que más tarde alcanzaría gran notoriedad al ser citada por Baumnan:

¿Qué es una familia en la actualidad?, ¿Qué significá Por supuesto, hay niños, mis niños, nuestros niños. Pero hasta la progenitura, el núcleo de la vida familiar ha empezado a desintegrarse con el divorcio (...) Abuelas y abuelos son incluidos y excluidos, sin recursos para participar en las deci- 
siones de sus hijos e hijas. Desde el punto de vista de los nietos, el significado de los abuelos debe determinarse por medio de decisiones y elecciones individuales (...) (Bauman, 2004, p. 12).

Estas palabras adquieren especial significación veinte años después, cuando "el por supuesto, hay niños" resulta ser una afirmación bastante cuestionada, dado el éxito del movimiento "chidfree" (Blackstone, 2019), ciertas legislaciones abren la puerta para la inclusión de las mascotas dentro de las categorías familiares (Handy, 2019), y cuando lo que se controvierte no es la función del abuelo, sino el significado las más básicas nociones de "madre", "matrimonio" "familia", "hijo", etc.

En parte, esta fluctuación está relacionada con los paradigmas teóricos, desde los cuales se entiende la significación y el lenguaje, pues desde algunas de las coordenadas teóricas más aceptadas de la era presente no existen significados fijos. Términos y conceptos se van definiendo y redefiniendo perpetuamente según un fluir social y dialogal.

Teorías como el constructivismo social y, más aún, el interaccionismo simbólico son típicas de este modo de comprender la significación. Así, por ejemplo, desde las coordenadas del interaccionismo simbólico, el significado deriva de la interacción social y puede ser manipulado o modificado por un proceso interpretativo-constructivo. Asimismo, el constructivismo social sostendrá que el lenguaje no es ideológicamente neutro, ni contentivo de significación objetiva. Y no "refleja pasivamente una estructura conceptual pre-existente; sino que por el contrario, está activamente implicado en crear estructuras, el lenguaje no simplemente corresponde, refleja o describe la experiencia humana sino que la <<interpreta>> o, mejor dicho, la construye" (Kilpert, 2003).

El peso de esta forma de entender la significación, se hace evidente en ámbitos como, por ejemplo, el de la discusión sobre el género, en el que explícitamente se plantea como meta legítima y positiva la redefinición de conceptos y estructuras.

Pero además de dichos paradigmas, la aparición de nuevos fenómenos y prácticos introduce vaguedad o ambigüedad, en términos que, hasta el momento, habían carecido de ella. Así, hasta hace unas décadas, el término "madre biológica", era lo suficientemente claro. Empero, prácticas como la maternidad subrogada gestacional (es decir, en la que la madre gestante no aporta el óvulo) se introducen oscuridad en la cuestión (Alvares, 2015). Igualmente, el hecho de que personas que se identifiquen como hombres conciban, gesten y den a luz genera un nuevo campo de ambigüedad sobre el significado de palabras como "hombre", "mujer", "madre" o "padre" (Verlinden, 2012). Ello no nece- 
sariamente quiere decir que, efectivamente, opere un cambio de significado o que haya que ampliar la noción de "varón" para incluir a seres capaces de dar a luz. Lo que significa es que, la claridad lingüística decrece a la luz de los nuevos fenómenos sociales y relacionales, de modo que las posibilidades de desacuerdo puramente lingïstico se incrementan.

\section{INCONVENIENTES RELATIVOS A LAS REGLAS DE RAZÓN}

En el acápite anterior se señalaron ciertas dificultades y escenarios que dificultan el diálogo en materia de género por no cumplir del todo las reglas fundamentales que, como se señaló anteriormente, hacen posible la comunicación entre los hablantes. Al lado de estas reglas, la teoría de la argumentación, y más concretamente, la línea alexiana, que aquí se toma como punto de referencia, señala una serie de condiciones para que la comunicación satisfaga estándares de racionalidad y apertura. A estas úlitmas se les llama "reglas de razón".

El cóntenido básico de las reglas de razón es sintetizado por Alexy en la siguiente cláusula.

$<<$ Todo hablante debe, cuando se le pide, fundamentar lo que afirma, a no ser que pueda dar razones que justifiquen el rechazar una fundamentación >> (Alexy, 2017, p. 406).

Esta regla se desglosa, a su vez, en las siguientes exigencias (se cita textualmente de Alexy, incluyendo la numeración interna que aparece en la obra):

(2.1) Quien pueda hablar puede tomar parte en el discurso.

La segunda regla regula la libertad de discusión. Puede sub- dividirse en tres exigencias:

(2.2) (a) Todos pueden problematizar cualquier aserción. (b) Todos pueden introducir cualquier aserción en el discurso. (c) Todos pueden expresar sus opiniones, deseos y necesidades.

(c) es importante especialmente en el discurso práctico. Finalmente, la tercera regla tiene la función de proteger el discurso de la coerción. Se enuncia así:

(2.3) A ningún hablante puede impedírsele ejercer sus derechos fijados en (2.1) y (2.2), mediante coerción interna o externa al discurso (Alexy, 2017, p. 271). 
Un examen somero de las dinámicas de diálogo en materia de género es suficiente para entender que son muy frecuentes las ocasiones en las que estos supuestos no se cumplen.

Lo primero que parece notorio es que en los diálogos sobre temas de género no siempre se cumple la exigencia de apertura. Ello ocurre en muchas formas y en muy distintos contextos. Por una parte, subsisten lugares, especialmente en culturas muy tradicionalistas, en los que existen restricciones legales y culturales para que ciertos sectores se manifiesten. Los ejemplos son bastante conocidos. Es sabido que hay países en los que sigue siendo ilegal la participación política de la mujer y las prácticas homosexuales son prohibidas y penalizadas con la muerte. En otros contextos, menos radicales, la palabra de la mujer simplemente es menospreciada y la simple cuestionamiento de una arraigada tradición patriarcal conllevaría en el mejor de los casos la burla y en el peor una reacción violenta. No es para nadie un secreto el peligro que conlleva defender ideas feministas (de cualquier tipo) en países como Arabia Saudita (Tønnessen, 2016, p. 18) y mucho más aún reclamar el respeto de los derechos de los homosexuales (Human Rights Watch, 2018). Tampoco es posible desconocer que en el mundo occidental, existen restricciones violentas a la expresión de ciertas ideas asociadas y a la participación de ciertos hablantes en los discursos de género. Es un dato comprobado que en América Latina existen agresiones selectivas hacia la población homosexual, que en algunos casos toma la modalidad de persecusión contra líderes de colectivos LGTBI. Esta violencia ha llegado a extremos de mal llamada "limpieza social", asesinatos, violaciones, lesiones personales, etc (Unidad de Datos EL TIEMPO, GDA y colaboradores, 2018) y es muy claro que aunque la realidad urbana sea muy diferente, en algunos sectores rurales de latinoamerica la voz femenina -y mucho más aún la voz de los homosexuales- dista mucho de ser tenida en cuenta.

No se debe creer, sin embargo, que la exclusión de voces y discursos son exclusivas de las culturas de más acendrada tradición patriarcal o el mundo rural o las periferias del mundo ilustrado. Por el contrario, en ciertos contextos, como por ejemplo, los escenarios académicos o esfereas políticas y judiciales, aparece otro tipo de exclusión, otro tipo de dogmas incuestionables e incluso, violencia física. En concreto, hay contextos en los que una manera específica de entender el género y el sexo se ha convertido en dogma incuestionable y quienes disienten son sometidos a formas de marginación. Nótese que se evita deliberadamente emplear expresiones como "el discurso de género se ha convertido en dogmático" o "el feminismo ha degenerado en ideología incuestionable". Ello obedece a la necesidad de no atribuir estas actitudes globalmente a todos los estudiosos de género a todos los feministas. De hecho, algunos de los defensores del feminismo o de los derechos de la población homosexual se 
han convertido en verdaderos parias dentro de las comunidades académicas, justamente por no adherirse a una visión monilítica.

Especialmente en el ámbito académico se observa cómo, el simple cuestionamiento de datos, análisis estadísticos o narrativas vinculadas con la comprensión poestructuralista del género, puede desatar situaciones rayanas en el linchamiento. Ya se ha mencionado cómo auténticas feministas que, sin embargo, son escépticas respecto de ciertas aseveraciones y pretensiones de una forma de feminismo predominante en el mundo académico americano, son recibidas en medio de protestas, algunas de ellas violentas. Su "delito" cultural, dista mucho del cuestionamiento de los logros del feminismo o la negación de la dignidad de la mujer. En algunos casos, se trata del simple cuestionamiento de estadísticas ampliamente difundidas sobre la violencia contra la mujer, o de la magnitud de la diferencia salarial.

El monopolio casi exclusivo de una versión muy específica del feminismo en los departamentos de Gender Studies y Women's Studies, ha tenido como consecuencia la adopción de una suerte de credo y de nuevas formas de herejías. Y en muy diversas latitudes, los profesores que cuestionan esta nueva ortodoxia, son marginalizados y, sometidos a auténtica coerción. El descrédito y el despido son riesgos muy concretos que puede correr alguien que, por ejemplo, no crea en la total culturalidad de masculinidad y feminidad.

Aparte de ello, se observa una creciente estigmatización por razón de religión o postura filosófica e incluso, una legitimación de lo que se admite públicamente como discriminación, en aras de la protección de los "avances en materia de género". Explícitamente se sostiene en distintos medios que la admisión de creyentes o de personas filosóficamente opuestas a las visiones "oficializadas" del género, constituyen peligro para la sociedad libre. Así, por ejemplo, en un artículo difundido en un medio de comunicación colombiano de amplia circulación, un columnista escribió lo siguiente respecto de dos candidatos a la Corte Constitucional:

No elegir a (...) por sus convicciones religiosas sería un acto de discriminación y nada sería más paradójico que el acto de elección de un miembro de la Corte Constitucional sea el resultado de eso, pero elegirlos puede poner en riesgo decisiones que quienes somos liberales consideramos como avances ejemplares en el reconocimiento de los derechos y las libertades en Colombia (Riveros, 2017).

Ahora bien, parece incontrovertible que la anatematización y la persecución que sufren quienes se atreven a cuestionar los paradigmas de género en lugares como el medio oriente o la violencia que sufren los líderes homosexuales 
en ciertas regiones de occidente, no son comparables con las situaciones recién descritas. Desde luego que resulta más irracional el consenso obtenido bajo la amenaza de muerte a líderes feministas o Lgtbi en lugares como Arabia Saudita, que la exclusión de profesores que, por ejemplo, no estén de acuerdo con el uso de los llamados "gender neutral pronouns".

Sin embargo, la intolerancia y el radicalismo no son retroceso en sociedades intolerantes y radicales, simplemente es mantenimiento del status quo. En cambio, la exclusión por razones de pensamiento o religión en sociedades que tradicionalmente han sido baluartes del debate, la investigación y la confrontación libre del pensamiento, supone un auténtico paso hacia atrás. Que en una universidad exista un auténtico riesgo físico por expresar una idea, es algo que contradice la esencia misma de la instutución universitaria. Que una democracia occidental moderna prácticamente exija la apostasía para el acceso a los cargos públicos es antidemocrático.

Por lo demás, que los espacios paradigmáticos de la discusión, como la academia, se encierren en una posición y en una forma monista de interpretación comporta un grave peligro social. Excluir a las posturas críticas del ámbito universitario no quiere decir eliminar este tipo de pensamiento. Lo que quiere decir es que se le confina a expresarse fuera de un ámbito cualificado, en el que se exige rigor en la prueba y en la argumentación. Los discursos "marginalizados" pueden quedar relegados así a la discusión panfletaria, al intercambio de eslóganes. En últimas, la pretensión de exclusión de figuras como John Finnis de las aulas universitarias, no contribuye a la desaparición de formas de pensamiento críticas a las posturas académicas más difundidas. Contribuye, en cambio, a que la vocería de estas críticas sea asumida por periodistas, o incluso por comediantes. El paper académico desaparecerá y será reemplazado por el panfleto, tipo de publicación, por esencia sustraido de la revisión y del rigor.

Aparte de los supuestos de exclusión abierta y de coerción institucional o semiinstitucional, cabe señalar que uno de los rasgos más notorios de la política de identidades, dentro de la cual se inscriben algunas formas del discurso de género, consiste en la limitación de la legitimidad para intervenir en el diálogo. Así, parece que conforme se consolida la política de las identidades se difunde la idea de que sólo quienes pertenecen a ciertos grupos deben opinar sobre las problemáticas propias de esos colectivos. Así, por ejemplo, CoralOrdóñez, siguiendo a Bharmbra y Margee (2010), alerta sobre lo que ella llama riesgos del esencialismo y las políticas excluyentes.

Bhambra y Margree (2010) llaman "políticas excluyentes" y "reificación de identidades" a los efectos conservadores que han acompañado el concepto de 


\begin{abstract}
"identidad". Las políticas excluyentes no son nuevas, la idea de la política fundamentada en solidaridades desde la igualdad o similitud (sameness) tiene una larga historia en la tradición crítica. Desde que Marx conceptualizó desde el punto de vista del proletariado, ha sido usado por las teóricas feministas, así como por los poscoloniales en términos de subalterno, y más recientemente desde el punto de vista de los parias de la India. "Sin embargo, aunque el uso de la identidad como base de la acción política se ha considerado poderoso (y efectivo), también se considera cada vez más problemático. Por ejemplo, la política excluyente de movimientos como el poder negro, el feminismo tanto radical como lésbico y, por último, los movimientos por la pureza étnica o la integridad religiosa, o ambos, han generado una profunda preocupación con el programa de separación y el aislacionismo en el que a menudo basan tales movimientos. Para muchos críticos, es aún más preocupante el afirmar que solo las mujeres pueden ser feministas, o que solo los negros pueden trabajar contra el racismo, o que solo los parias pueden luchar contra las opresiones de castas (...) (Coral-Ordóñez, 2019, p. 28).
\end{abstract}

Este tipo de tendencias, claramente es incompatible con la premisa de apertura del diálogo, pero, sobre todo, al particularizar el espectro de los hablantes sobre temas que, en definitiva, son de derechos humanos, relativizan la fuerza de los imperativos de acción respecto de estos últimos. Una de las consecuencias de los derechos humanos, en tanto exigencias que emanan directamente de la dignidad común a todos los miembros de la familia humana, es que su violación no puede dejar indiferente a nadie. La violación de los derechos humanos debe ser un asunto que concierne a toda la humanidad, justamente, porque suponen un desconocimiento de lo que exige la condición humana.

\title{
5. A MODO DE CONCLUSIÓN Y REMISIÓN FINAL
}

Las irregularidades lógicas que se han reseñado hasta el momento explican parcialmente algunas de las peculiaridades del debate en torno al género y los peligros que comporta abandonar los estándares de racionalidad en la discusión en un tema como este. Que las discusiones sobre temas que afectan directamente la dignidad humana, el concepto de familia, la seguridad personal, las libertades ideológicas, y la educación de los jóvenes carezcan de las condiciones mínimas que permiten que las partes lleguen a entablar un auténtico diálogo parece la receta perfecta del malestar social a corto o largo plazo. Las consecuencias del actual intercambio de eslóganes que remeda el diálogo social trascienden el ámbito de lo directamente concerniente con los asuntos de género. Por el contrario, las disfuncionalidades dialógicas reseñadas afectan la idea misma de comunidad política, las reglas básicas de la cooperación y la amistad cívica. 
Ahora bien, es necesario reseñar que en cierto modo, estas irregularidades impregnan el debate público en general. Tal vez sea menester aceptar que el género es solo una de esas áreas en las que la incapacidad de diálogo de los tiempos presentes se hace evidente. Se requiere, pues, que la investigación sobre las disfuncionalidades del diálogo social en la era posmoderna se profundice y generalice. Que el análisis se extienda a otras áreas particularmente problemáticas como la inmigración.

Igualmente, se advierte que en el caso específico del género parte de las disfuncionalidades dialógicas se deben a problemas conceptuales que deben ser atendidos por disciplinas como la Filosofía o la Filosofía del Derecho. Por ejemplo, en las discusiones sobre la "naturalidad" de homosexualidad, parte del desacuerdo se deriva de la fragmentación del concepto de naturaleza. En últimas, gran parte de los hablantes apelan al derecho natural (aquello frente a lo cual no cabe oponer el argumento mayoritario), pero presentan discursos paralelos. Igual sucede con conceptos básicos como libertad, individuo, inclinación. En tanto estos conceptos presenten el alto grado de ambigüedad que de momento presentan, el diálogo será intercambio entre sordos. Y la tarea de desambiguación del lenguaje en este sentido (aunque no sea su única ni principal tarea) solo puede acometerse en un nivel de reflexión filosófica.

\section{REFERENCIAS}

Alexy, R. (2017). Teoría de la argumentación jurídica. La teoría del discurso racional como teoría de la fundamentación jurídica (M. Atienza \& I. Espejo, Trads.). Lima: Palestra.

Alvares, C. (2015). Between the social and the biological: rethinking maternity in light of new techniques of assisted reproduction. Revista Lusófona de Estudos Culturais, 3(1), 99-110.

Aristóteles. (1985). Ética Nicomáquea - Ética Eudemia (P. B. Julio, trad.). Madrid: Gredos.

Barceló Aspeitia, A. A. (2004). ¿Qué sabe ellá ¿Quién hace lógicá Lógica y Feminismo. Memorias del VII Encuentro Internacional de Didáctica de la Lógica, 35-44. Recuperado de http://www.filosoficas.unam.mx/ abarcelo/PDF/feminismo.pdf

Bauman, Z. (2004). Modernidad líquida (1 edition; F. de C. Economica, Ed.; J. A. Squirru \& M. Rosenberg, Trads.). Fondo de Cultura Económica.

Bhambra, G.., \& Margree, V. (2010). Identity Politics and the Need for a "Tomorrow". Economic and Political Weekly, 45(15), 59-66. Recuperado de JSTOR.

Blackstone, A. (2019). Childfree by Choice: The Movement Redefining Family and Creating a New Age of Independence. Dutton. 
Coral-Ordóñez, M. (2019). La amistad cívica como respuesta a la política de identidades (Trabajo de grado para obtener el título de politóloga). Universidad de La Sabana.

de la Calle Lombana, H. (2016a, julio 24). Declaración de Humberto de la Calle sobre el enfoque de género en los acuerdos. Equipo Paz y Gobierno. Recuperado de http:/ / equipopazgobierno.presidencia.gov.co/prensa/declaraciones/Paginas / humberto-calle-habla-sobre-inclusion-enfoque-genero-acuerdospaz.aspx

de la Calle Lombana, H. (2016b, octubre 16). Enfoque de género. El enfoque de género corresponde exactamente a los principios constitucionales vigentes. El Tiempo. Recuperado de https:/ / www.eltiempo.com/opinion/columnistas/humberto-dela-calle/enfoque-de-genero-humberto-de-la-calle-columnista-el-tiempo-53007

Handy, M. C. (2019). The "De-Chattelization" of Companion Animals through Family Law Legislation: How Alaska's H.R. 147 Has Dismantled the Traditional Property Law View of Pets. The Changing Face of Family Law, 52(1).

Hass, M. (1998). Feminist of Aristotelean Logic. En C. A. Freeland (Ed.), Feminist Interpretations of Aristotle. University Park, Pennsilvania: Penn State University Press.

Human Rights Watch. (2018). Audacity in Adversity. LGBT Activism in the Middle East and North Africa [Non-profit]. Recuperado de LGBT activists and artists from Arabic-speaking countries website: https://www.hrw.org/report/2018/04/16/ audacity-adversity/lgbt-activism-middle-east-and-north-africa

Irigaray, L. (2008). In Science, is the Subject Sexed? En G. Gutting (Ed.), Continental Philosophy of Science (pp. 283-292). https:/ / doi.org/10.1002/9780470755501.ch21

Kilpert, D. (2003). Getting the full picture: A reflection on the work of M.A.K. Halliday. Language Sciences, 25(2), 159-209.

Márquez, N., \& Laje, A. (2016). El Libro Negro de la Nueva Izquierda: Ideología de género o subversión cultural (1 edition). Grupo Unión.

Miralles, Á. A., Castilla de Cortázar, B., \& Miranda Novoa, M. I. (2017). Los discursos sobre el géneró: algunas influencias en el ordenamiento jurídico español. Valencia: Tirant Humanidades.

Nye, A. (1990). Words of Power: A Feminist Reading of the History of Logic. New York: Routledge.

Nye, A. (1998). Semantics. En M. Jaggar \& I.. Young (Eds.), A Companion to Feminist Philosophy. London: Routledge. 
Ordóñez Maldonado, A. (2016). Acuerdo Santos/Timochenko es una imposición de la ideología de género. Recuperado de https://www.youtube.com/watch?v= gh3Gd4 gv0mM

Radosh, P.. (2009). Abortion a sociological perspective. En S.. Martinelli-Fernández, L. Baker-Sperry, \& H. McIlvaine-Newsad (Eds.), Interdisciplinary views on abortion: Essays from Philosophical, Sociological, Anthropological, Political, Health and other perspectives. Jefferson, North Carolina: McFarland \& Co.

Ricoeur, P. (1999). Freud: una interpretacion de la cultura. México: Siglo XXI.

Rivelis, G. (2009). Freud. Una aproximación a la formación profesional y la práctica docentes. Noveduc Libros.

Riveros, H. (2017, abril 15). Magistrada (o), ¿usted a qué religión pertenecé La Silla Vacía. Recuperado de https:/ / lasillavacia.com/historia/magistrada-o-usted-quereligion-pertenece-60552

Sánchez Cristo, J. (2016, diciembre 10). En los acuerdos de paz aparece encriptada la ideología de género: Alejandro Ordoñez. En Entrevistas W. Recuperado de https:/ /www.wradio.com.co/escucha/archivo_de_audio/en-los-acuerdos-de-paz-aparece-encriptada-la-ideologia-de-genero-alejandro-ordonez/20161012/oir/ 3271857.aspx

Tønnessen, L. (2016). Women's Activism in Saudi Arabia: Male Guardianship and Sexual Violence (Núm. CMI Report R 2016:1). Recuperado de Chr. Michelsen Institute website: https://www.cmi.no/publications/file/5696-womens-activism-insaudi-arabia.pdf

Unidad de Datos EL TIEMPO, GDA y colaboradores. (2018, de enero). Crímenes contra LGBT, una realidad invisible. En diez países de América aumentan los crímenes contra LGBT. EL TIEMPO y GDA lo investigaron. El Tiempo. Recuperado de https:/ / www.eltiempo.com/datos/cifras-de-crimenes-contra-la-comunidad-lgbten-latinoamerica-159558

Verlinden, J. (2012). Transgender Bodies and Male Pregnancy: The Ethics of Radical Self-Refashioning. En M. Michaela Hampf \& M. A. Snyder-Körber (Eds.), Machine: Bodies, Genders, Technologies. Heidelberg: Winter. 
